\title{
DNA Replication Induction
}

National Cancer Institute

\section{Source}

National Cancer Institute. DNA Replication Induction. NCI Thesaurus. Code C40827.

DNA Replication Induction involves initiation of activities of biologic molecules or complexes involved in the process by which the two strands of a DNA double helix separate and each strand acts as a template for the synthesis of a complementary strand by specific base pairing. 